\title{
SEMIOTIKA BATIK LARANGAN DI YOGYAKARTA
}

\author{
Rina Patriana Chairiyani \\ Character Building Development Center (CBDC), BINUS University \\ Jln. Kemanggisan Ilir III No. 45, Kemanggisan - Palmerah, Jakarta 11480 \\ patriana_rina@yahoo.com
}

\begin{abstract}
Batik is a part of Indonesian heritage and culture. In Yogyakarta, there is known as Batik Larangan. The pattern of this Batik is used as identity and status. For the Javanese, Batik is not just a fashion; moreover, it contains philosophy and beliefs closely related to daily life. Batik also becomes identic to the greatness of the leader that considers having a power to increase his authority. By using qualitiative methodology, this study writes about how the semiotic concept can be used on art and culture study in Javanese people.
\end{abstract}

Keywords: semiotics, Batik, culture, Indonesian heritage

\begin{abstract}
ABSTRAK
Batik merupakan warisan budaya Indonesia. Di Yogyakarta terdapat motif batik yang dikenal dengan sebutan Batik Larangan. Pada dasarnya motif batik tersebut digunakan sebagai refleksi identitas dan status seseorang. Bagi Masyarakat Jawa, Batik bukan sekadar fashion, melainkan juga sarat dengan filosofi dan kepercayaan yang dekat dengan kehidupan mereka sehari-hari. Batik juga menjadi simbol kebesaran bagi seorang pemimpin untuk mendapatkan legitimasi kepemimpinannya. Dengan menggunakan metodologi kualitatif, penelitian ini mengemukakan tentang bagaimana konsep semiotika dapat digunakan dalam kajian seni dan budaya dalam masyarakat Jawa.
\end{abstract}

Kata kunci: semiotika, Batik, budaya, warisan Indonesia 


\section{PENDAHULUAN}

Di Nusantara teknik batik berkembang sangat pesat. Konon, kata batik berasal dari bahasa Jawa, yaitu amba yang berati menulis, dan nitik yang berati membuat titik (Wahyu, 2012:4). Namun sejarah batik di Indonesia berkaitan erat dengan perkembangan kerajaan Majapahit dan kerajaankerajaan setelahnya. Dari beberapa catatan, perkembangan batik terjadi pada zaman kerajaan Mataram dan berlanjut pada masa kejayaan kerajaan di Yogyakarta dan Surakarta. Bagi masyarakat Yogyakarta dan Surakarta, batik bukan sekadar benda tekstil yang akan menjadi busana, melainkan batik juga mengandung filosofi dan kepercayaan yang berkaitan erat dengan kehidupan sehari-hari baik di dalam maupun di luar lingkungan keraton.

Di lingkungan keratin batik memperoleh kekuatan dan penafsiran yang paling eksplisit, batik menjadi busana kebesaran bagi raja dan kerabatnya. Oleh karena itu, pusat seni batik selalu berada di dalam keraton. Seni batik selalu dirawat dan disempurnakan, sehingga akhirnya batik mencapai kesempurnaan penggarapan dan kedalaman rasa, serta menjadi salah satu seni utama keraton-keraton di Jawa Tengah. Hal ini sesuai dengan konsepsi sosiologi Jawa yang menyatakan bahwa keraton adalah pusat atau kota raja sebagai pencipta seni dan masyarakat luarnya hanya sebagai penikmat.

Pada awalnya batik hanya dibuat di kalangan kerabat keraton dan hanya dikenakan oleh keluarga kerajaan dan punggawa. Punggawa keraton yang tinggal di luar istana yang membawanya ke luar. Keluarga mereka membuatnya di tempat mereka masing-masing. Lama-kelamaan seni batik ditiru oleh masyarakat umum dan selanjutnya menjadi pekerjaan kaum wanita di waktu senggang. Lambat laun, batik yang tadinya hanya dikenakan oleh keluarga kerajaan, menjadi pakaian rakyat yang disukai wanita dan pria (Wahyu, 2012:7).

\section{Batik Larangan di Yogyakarta}

Pada dasarnya batik Yogyakarta banyak menggunakan latar belakang berwarna putih, warna motif terang atau kontras, namun jarang menggunakan isen-isen penuh dan jika menggunakan perada, diterapkan pada seluruh motif sehingga batik terkesan mewah. Ragam motifnya seputar garis silang (motif ceplok dan kawung), garis miring (motif lereng atau parang) dan anyaman atau limaran. Ada pula motif non geometris, misalnya bunga, burung, naga, awan, gunung dan sebagainya (Wahyu, 2012:14)

Awalnya batik hanya dibuat di kalangan kerabat keraton dan hanya dikenakan oleh keluarga kerajaan dan punggawa. Kain batik yang khusus dipakai oleh kaum bangsawan keraton, sarat dengan lambang dan makna serta halus pengerjaannya. Di samping itu, ada aturan-aturan pemakaian corak kain, baik menurut tingkat kedudukan seseorang maupun peristiwa pada waktu apa kain tertentu dipakai. Lama-kelamaan seni batik ditiru oleh masyarakat umum dan selanjutnya menjadi pekerjaan kaum wanita di waktu senggang. Lambat laun, batik yang tadinya hanya dikenakan oleh keluarga kerajaan, menjadi pakaian rakyat yang disukai wanita dan pria (Wahyu, 2012:7)

Mulai akhir abad ke-18, Sultan Yogyakarta dan Sunan Surakarta menentukan beberapa pola batik sebagai pola "larangan" (Himpunan Wastraprema, 1990:36). Akibatnya ada batik tertentu yang disebut sebagai batik larangan. Aturan-turan tentang tata cara pemakaian batik ini pada masa Sultan Hamengku Buwono VIII dapat dilihat dalam Pranatan Dalem Bab Namanipun Panganggo Keprabon Ing Nagari Dalem Ngayogyakarta Hadiningrat yang dikeluarkan pada 3 Mei 1927. Batik larangan itu dijadikan sebagai pakaian kebesaran (busana keprabon) di kalangan bangsawan keraton. Untuk pakaian kebesaran umumnya kain batik itu berbentuk kampuh/dodot. Adapun batik yang sekaligus merupakan batik larangan sesuai dengan peraturan Sultan Hamengku Buwono VIII adalah: (1) Parang Rusak Barong, (2) Parang Rusak Gendreh, (3) Parang Rusak Klitik, (4) Semen Gede Swat Gruda, (5) 
Semen Gede Swat Lat, (6) Udan Riris, (7) Rujak Sente, (8) Parang-parangan. Pada dasarnya Batik Larangan adalah batik-batik tertentu yang dilarang pemakaiannya untuk masyarakat umum dan hanya khusus diperuntukkan bagi kalangan terbatas dalam masyarakat keraton saja.

Permasalahan yang diangkat dalam tulisan ini adalah tentang makna yang ditampilkan dalam motif Batik Larangan di Yogyakarta. Tujuan dilakukan penelitian ini secara khusus adalah untuk mengetahui bagaimana makna yang terdapat dalam motif Batik Larangan. Sedangkan tujuan secara umum adalah untuk mengetahui bagaimana konsep-konsep semiotika diterapkan dalam bidang seni dan kehidupan budaya masyarakat Yogyakarta.

\section{Semiotika}

Semiotika adalah sebuah ilmu tentang tanda.Ada dua cara pendekatan mengenai tanda yang secara umum diketahui yaitu pendekatan oleh Ferdinand de Saussure (linguis Swiss 1857-1893) dan pendekatan Charles Sanders Pierce (filsuf Amerika 1893-1914). Dilihat sudut orientasi akademis, Pierce mengembangkan sistemnya dalam kerangka filsafat. Sedangkan Saussure dalam kerangka linguistik (Sarwono, 2009).

Pierce mengemukakan teori segitiga makna atau triangle meaning yang terdiri dari 3 elemen utama, yakni tanda (sign), objek, dan interpretant. Tanda adalah sesuatu yang berbentuk fisik yang dapat ditangkap oleh pancaindera manusia dan merupakan sesuatu yang merujuk (mempresentasikan) hal lain di luar tanda itu sendiri. Tanda menurut Pierce terdiri dari simbol (tanda yang muncul dari kesepakatan), ikon (tanda yang muncul dari perwakilan fisik) dan indeks (tanda yang muncul dari hubungan sebab-akibat). Sedangkan acuan tanda ini disebut objek. Objek atau acuan tanda adalah konteks sosial yang menjadi referensi dari tanda atau sesuatu yang dirujuk tanda.Interpretant atau pengguna tanda adalah konsep pemikiran dari orang yang menggunakan tanda dan menurunkannya ke suatu makna tertentu atau makna yang ada dalam benak seseorang tentang objek yang dirujuk suatu tanda. Hal yang terpenting dalam proses semiosis adalah bagaimana makna muncul dari sebuah tanda ketika tanda digunakan orang saat berkomunikasi. Sedangkan Saussure membagi semiotik menjadi dua (2) bagian (dikotomi) yaitu penanda (signifier) dan pertanda (signified).Penanda dilihat sebagai bentuk/wujud, sedangkan pertanda dilihat sebagai makna yang terungkap melalui konsep, fungsi atau nilai-nilai yang terkandung di dalam bentuk/wujud tersebut. Eksistensi semiotika Saussure adalah relasi antara penanda dan petanda berdasarkan konvensi, biasa disebut signifikasi. Kesepakatan sosial diperlukan untuk dapat memaknai tanda tersebut (www.isi-dps.ac.id/berita/semiotika)

Pada dasarnya semiotika merupakan sebuah kajian mengenai makna yang terkandung dalam tanda, simbol maupun gambar. Baik Pierce maupun Saussure mengemukakan tentang bagaimana sebuah tanda,symbol, atau gambar dapat memiliki makna atau arti.

\section{METODE}

Penelitian ini menggunakan pendekatan kualitatif, terutama untuk mengkaji bagaimana makna yang terkandung dalam motif Batik Larangan. Oleh karenanya penelitian ini menggunakan metode analisis semiotika untuk mengungkap makna yang ada dalam objek kajian peneliti yaitu Batik Larangan yang terdapat di Keraton Yogyakarta. Unit analisis yang akan diteliti adalah arti/makna yang muncul dalam motif yang terdapat dalam batik-batik tersebut. 


\section{HASIL DAN PEMBAHASAN}

\section{Makna-makna Semiotika Batik Larangan}

Berdasarkan teori segitiga makna (triangle meaning) yang dikemukakan oleh Pierce, bahwa ada tiga elemen utama dalam makna, yakni tanda (sign), objek, dan interpretant. Tanda adalah sesuatu yang berbentuk fisik yang dapat ditangkap oleh panca indera manusia dan merupakan sesuatu yang merujuk (mempresentasikan) hal lain di luar tanda itu sendiri. Tanda menurut Pierce terdiri dari simbol (tanda yang muncul dari kesepakatan), ikon (tanda yang muncul dari perwakilan fisik), dan indeks (tanda yang muncul dari hubungan sebab-akibat). Bagian-bagian tersebut akan digolongkan sesuai dengan makna dan pengertian yang ada padamasing-masing kain, untuk memperjelas kedudukannya dalam pendekatan semiotika.

\section{Ikon}

Yang termasuk ikon dalam Batik Larangan adalah sebagai berikut.

\section{Parang Rusak}

Motif Parang Rusak merupakan salah satu variasi dari kelompok parang dan masuk dalam golongan motif geometris. Parang rusak tersusun atas ornamen parang yang lazim disebut lidah api dan mlinjon. Deretan parang dalam kain ini digambarkan berderet secara tidak teratur dan menurut garis-garis. Pada bidang yang miring antara dua deret parang terdapat lisen motif mlinjon yang merupakan ciri dari kelompok ini. Parang rusak berasal dari kata parang dan rusak. Parang berarti belati atau pisau dan rusak berarti hancur atau binasa. Motif parang rusak ini merupakan ciptaan dari Sultan Agung (Susanto, 1973:226).

Menurut G.P. Rauffer dan H.H. Joynboll penciptaan kain parang rusak oleh Sultan Agung erat kaitannya dengan kegemarannya pada peperangan. Keterangan tersebut dihubungkan dengan serangan Sultan Agung kepada Pieter Zoon Coen, sehingga dianggap sebagai raja yang gemar peperangan. Padahal pengertian peperangan dalam alam pikiran orang Jawa tidak hanya semata-mata perang secara fisik, tetapi juga perang melawan nafsu jahat yang hidup dalam diri manusia (Kawindra Susanto, 1981: 11).

Ornamen parang rusak atau lidah api mengandung makna kesaksian untuk memberantas musuh, bagaikan dewa api yaitu Bathara (Susanto, 1973: 276). Api merupakan salah satu unsure hidup, dalam diri manusia terdapat unsur api yaitu ambisi atau amarah. Jika manusia tidak dapat mengendalikan amarahnya maka lambat laun akan tergelincir, sedangkan mlinjon sering juga disebut sebagai ornamen blumbangan. Blumbangan sama artinya dengan blumbang (tempat air). Jadi ornamen blumbangan digambarkan sebagai lambang tempat air yang suci, air yang dapat melangsungkan kehidupan, bagai kan dewa laut. Dewa laut melambangkan sosok dewa yang memiliki sifat lapang dada (lapang hati) (Susanto, 1973: 276). Dalam diri manusia sebetulnya memiliki sifat lapang hati seperti halnya air lautan namun jika diabaikan akan tergelincir. Masyarakat yang dapat mengendalikan amarah dan memiliki sifat lapang hati akan menemukan kesempurnaan batin. Perilaku yang demikian itu dalam konsepsi kekuasaan Jawa tradisional haruslah dimiliki oleh seorang raja yang ideal, karena raja berkewajiban untuk memberikan teladan dan rakyatnya akan mengikuti tindakannya apakah itu "baik" atau "jahat". Jadi perilaku raja merupakan faktor penentu bagi keadaan dalam kerajaannya (Surat Yasadipura I dalam Moertono 1985:59). Karena motif itu mengandung arti yang dalam bagi seorang raja, maka motif ini khususnya Parang Rusak Barong hanya dipakai oleh raja. 
Ukuran motif parang rusak terbesar sering disebut Parang Rusak Barong, sedangkan Parang Rusak Gendreh dalam pembuatan motifnya tidak boleh lebih dari $8 \mathrm{~cm}$ dan tidak boleh kurang $4 \mathrm{~cm}$ dan Parang Rusak Klitik ukuran motifnya lebih kecil dari Parang Rusak Gendreh (Himpunan Wartaprema, 1991: 28; Susanto, 1973:276).

\section{Semen Gede Sawat Gruda}

Motif Semen Gede Sawat Gruda masuk dalam kelompok yang tersusun atas bunga, daun dan gruda (garuda). Semen Gede Sawat Gruda berasal dari kata Semen, Gede, Sawat, dan lar. Semen berarti semi atau tumbuh, gede berarti besar, sawat mempunyai arti sayap, sedangkan gruda adalah garuda. Motif ini terdiri dari unsur meru, binatang, tumbuhan, pohon kuat, burung dan gruda. Makna simbolik pada motif semen gede sawat gruda dapat diungkapkan oleh unsur yang ada pada motif ini. Meru melambangkan puncak gunung yang tinggi. Gunung yang dalam konteks kepercayaan Jawa merupakan tempat para dewa, selain melambangkan gunung, meru juga melambangkan bumi atau tanah tempat segala yang hidup bersemi (Soerjanto, 1911: 25).

Binatang, merupakan satwa yang hidup di hutan, hutan yang tumbuh di atas bui, sehingga binatang yang hidup di hutan menyebabkan adanya saling ketergantungan adanya mata rantai yang selalu berputar. Binatang juga melambangkan keperkasaan. Tumbuhan, sering diidentikan dengan pohon hayat, pohon yang dalam pewayangan digunakan sebagai gunungan. Tumbuhan memiliki makna kemakmuran.

Pohon hayat, kerap dilukiskan berupa sulur-sulur berdaun rimbun mengikal ke kiri dan ke kanan, tak putus-putusnya dan berpangkal pada sebuah bonggol. Tanaman sulur berbonggol merupakanlambang kehidupan. Kekuatan hidup yang mengalir dilambangkan dengan tangkai yang melentur berbelok-belok dan disetiap ruas bercabang atau beralih arah (Tirta dalam Femina, 1994: 78-79).

Burung, melambangkan penguasa dunia atas, penguasa yang mengatur udara, memiliki watak luhur. Gruda, melambangkan mahkota, penguasa tertinggi atau penguasa jagad dan isinya yang juga melambangkan kekuasaan dan kekuatan. Jadi dapat dikatakan bahwa motif batik semen gede sawat gruda secara keseluruhan memiliki makna agar pemakainya memiliki kedudukan yang tinggi dan hidup makmur namun berbudi luhur. Dia juga diharapkan dapat menyesuai kan diri dengan situasi dan kondisi sekitarnya, mempunyai kemauan yang tinggi untuk berusaha, sehingga hidupnya tidak hanya nrima ing pandum (menerima keadaan).

\section{Semen Gede Sawat Lar}

Motif Semen Gede Sawat Lar masuk dalam kelompok semen yang tersusun atas bunga, daun dan lar. Semen Gede Sawat Lar berasal dari kata semen, gede, sawat dan lar. Semen memiliki arti semi atau tumbuh, gede berarti besar, sawat lar memiliki arti sayap burung. Susunan ornamen motif ini adalah meru, lidah api, bangunan, sawat, tumbuhan, dan burung. Pada hakikatnya motif semen gede sawat lar sama dengan motif semen gede sawat gruda, hanya ada satu perbedaan yaitu terletak pada penambahan ornamen bangunan/tahta pada motif semen gede sawat lar. Arti simbolik dalam motif semen gede sawat lar ini dapat diungkapkan dari unsur-unsur yang ada. Unsur-unsur itu adalah sebagai berikut: (1) Meru, melambangkan gunung tertinggi, tempat bersemayam pada dewa, melambangkan bumi atau tanah tempat segala yang hidup bersemi; (2) Lidah api melambangkan nyala api, merupakan salah satu unsur hidup, dalam diri manusia api adalah amarah atau ambisinya yang bermakna kesaktian; (3) Bangunan, sering disebut sebagai singgasana atau istana atau tempat yang suci, melambangkan kekuasaan yang adil atau pengayoman yang penuh keadilan (Soerjanto, 1991:10); (4) Tumbuhan, sering diidentikkan dengan pohon hayat dan melambangkan kemakmuran. Burung, merupakan simbol dunia atas. 
Penguasa udara yang merupakan unsur penting bagi kehidupan manusia dan melambangkan budi yang luhur. Makna motif batik semen gede sawat lar ini hampir sama dengan motif batik semen gede sawat gruda, namun dapat disimpulkan bahwa makna motif batik semen gede sawat lar berarti pemakainya diharapkan memiliki kedudukan yang tinggi dan kesaktian untuk mengendalikan nafsunya, hidup makmur dan tinggal di tempat yang dapat mmberikan pengayoman yang penuh keadilan.

\section{Udan Riris}

Motif batik udan riris masuk dalam kelompok motif lereng yang mempunyai ciri berupa lajur-lajur yang membentuk sudut $40^{\circ}$, berisi ornamen-ornamen kecil yang diatur sedemikian hingga merupakan motif yang memperlihatkan gaya miring (Soerjanto, 1991: 24). Motif ini tersusun atas beberapa bentuk ornamen seperti banji sawut, parang untu walang, cinden, rangkaian bunga dan rangkaian kanung. Motif udan riris berasal dari kata udan dan riris. Udan sama artinya dengan hujan dan riris artinya gerimis. Jadi Udan Riris berarti hujan gerimis. Hujan gerimis dalam motif ini digambarkan dengan ornament kecil-kecil yang tersusun miring. Arti simbolis motif kain ini dapat diketahui dengan menguraikan satu persatu unsur-unsur yang ada di dalamnya (Soerjanto, 1991:19). Pertama, banji sawut melambangkan keberuntungan, kebahagiaan dan kesuburan. Kedua, parang melambangkan kekuatan. Ketiga, untu walang melambangkan kesinambungan, terus-menerus tak ada putusnya. Keempat, cinden memiliki kesamaan dengan ornamen untu walang yang melambangkan kesinambungan. Kelima, rangkaian bunga melambangkan kesucian. Keenam, rangkaian kawung melambangkan serba guna.

Secara keseluruhan dapat diambil maknanya, bahwa motif udan riris menggambarkan suatu rahmat yang tidak pernah putus walaupun dalam ukuran kecil, bagaikan hujan kecil-kecil (gerimis) yang tak henti-hentinya.

\section{Motif Rujak Sente}

Motif rujak sente masuk dalam kelompok lereng. Motif ini tersusun atas beberapa ornamen kecil-kecil, unsur-unsur itu adalah banji, parang, bunga, dan untu walang. Motif rujak sente berasal dari kata rujak dan sente. Rujak adalah sejenis makanan yang bahannya berasal dari buah-buahan yang diberi bumbu gula jawa, kencur, cabe, asam, trasi dan garam. Makanan ini biasanya digemari oleh anak-anak muda atau orang yang sedang ngidam. Sente adalah semacam tanaman keladi hijau yang berumbi besar dan berdaun lebar. Motif rujak sente ini pada dasarnya sama dengan motif udan riris, hanya perbedaannya motif rujak sente berlatar gelap, sedangkan udan riris berlatar putih.

\section{Motif Parang-parangan}

Motif Parang-parangan merupakan variasi dari kelompok parang. Jika parang rusak barong, parang rusak gendreh dan parang rusak klitik merupakan pengembangan dalam hal ukuran, motif parang-parangan merupakan pengembangan dalam ornamen. Motif parang-parangan tersebut antara lain: 1. Parang Kusuma (Kusuma berarti bunga); 2. Parang Centung (Centung adalah rambut tipis bagian depan kepala yang diatur atau hiasan mempelai wanita di kepala bagian depan); 3. Parang Curiga (curiga = keris); 4. Parang baris (baris-baris); 5. Parang menang; 6. Parang sobrah (sobrah adalah sulur); 7. Parang cantel (cantel = sebangsa padi-padian) (Kawindra Susanto, 1981: 12).

Sesuai dengan konsep ikon pada trikotomi Pierce, kesesuaian bentuk dan nama yang digunakan dapat dilihat langsung (secara visual). 


\section{Indeks}

Yang termasuk indeks Batik larangan yakni fungsi kain. Dalam masyarakat Yogyakarta Batik yang khas dipakai oleh kaum bangsawan, umumnya halus pembuatannya dan memiliki arti falsafah yang tinggi . Pada tahun 1785 Sultan Hamengku Buwono I mencanangkan pola batik Parang rusak sebagai pola larangan, sedangkan Sultan Hamengku Buwono VII mencanangkan pola batik Kawung sebagai pola larangan. Pada masa Sultan Hamengku Buwono VIII corak parang menjadi pedoman utama untuk menentukan derajat kebangsawanan seseorang. Selain corak parang, semen, sawat, dan udan riris juga menjadi penentu derajat kebangsawanan, Pranatan Dalem Bab Namanipun Panganggo Keprabon IngNagari Dalem Ngayogyakarta Hadiningrat yang dikeluarkan Sultan Hamengkubuwono VIII pada tanggal 3 Mei 1927 merupakan peraturan tentang tata cara penggunaan kain batik, di antaranya terdapat delapan motif batik larangan yang terdapat di dalam peraturan tersebut (Susanto, 1973: 223-225; Condronegoro, 1995: 24-26). Tata cara penggunaan kain batik tersebut, sebagai berikut.

Bagi putra sultan yang memperoleh sebutan kanjeng panembahan diperbolehkan memakai dodot blenggen parang rusak barong. Namun dia juga diperbolehkan memakai parang rusak gendreh, parang rusak klitik, semen gede sawat gruda, semen gede sawat lar, udan riris, rujak sente, dan parang-parangan. Demikian juga dengan bebet prajuritan dan bebetnya. Bagi putra sulung sultan yang bergelar kanjeng gusti pangeran adipati anom diperbolehkan memakai dodot blenggen, Parang rusak barong. Seperti halnya dengan kanjeng panembahan, kanjeng gusti pangeran adipati anom juga diperbolehkan memakai parang rusak gendreh, parang rusak klitik, semen gede sawat gruda, semen gede sawat lar, udan riris, rujak sente dan parang-parangan. Demikian juga dengan bebet prajuritan dan bebetnya. Bagi putra sultan dari permaisuri memakai dodot blenggen, mulai dari motif parang rusak gendreh, parang rusak klitik, semen gede sawat gruda, semen gede sawat lar, udan riris, rujak sente. Demikian juga dengan motif prajuritannya, sedangkanuntuk bebetnya dia boleh menggunakan mulai dari motif parang rusak barong dan seterusnya. Bagi putra sultan dari selirnya diperbolehkan memakai dodot dan bebet prajuritan, parang rusak gendreh, parang rusak klitik, semen gede sawat gruda, semen gede sawat lar, udan riris, dan rujak sente, sedangkan motif bebetnya mulai dari motif parang rusak barong dan seterusnya. Permaisuri sultan diperkenankan memakai kain bermotif sama dengan sultan, yaitu Parang rusak barong dengan ukuran ornamen terbesar. Bagi selir sultan diperbolehkan memakai dodot blenggen maupun bebet dengan motif parang rusak gendreh, dan seterusnya. Bagi istri pertama kanjeng gusti pangeran adipati anom diperbolehkan memakai kain bermotif sama dengan suaminya. Selir kanjeng gusti pangeran adipati anom diperbolehkan memakai dodot blenggen motif mulai dari parang rusak klitik, semen gede sawat gruda, semen gede sawatlar, udan riris, rujak sente, dan parang-parangan. Untuk bebetnya diperbolehkan memakai kain batik bermotif mulai dari parang rusak gendreh dan seterusnya. Bagi putra kanjeng gusti pangeran adipati anom diperbolehkan memakai dodot bebet prajuritan dan bebet, mulai dari motif parang rusak gendreh dan seterusnya. Bagi pangeran sentana diperbolehkan memakai dodot, bebet prajuritan dan bebet mulai dari motif parang rusak gendreh dan seterusnya. Sama dengan yang dipakai oleh putra kanjeng gusti pangeran adipati anom. Bagi istri pertama para pangeran sentana hanya diperbolehkan memakai dodot bermotif sama dengan suaminya. Selir para pangeran sentana hanya diperbolehkan memakai dodot bermotif mulai dari semen gede sawat gruda dan seterusnya. Bebetnya bermotif dari parang rusak gendreh dan seterusnya. Namun, dengan catatan baik istri pertama maupun selir para pangeran sentana tersebut, merupakan istri-istri resmi dan atas seizin sultan. Bagi cucu sultan diperbolehkan memakai dodot blenggen, bebet prajuritan bermotif mulai dari semen gede sawat gruda dan seterusnya. Sedangkan bebetnya bermotif menulai dari parang rusak gendreh dan seterusnya. Bagi buyut sultan diperbolehkan memakai dodot dan bebet prajuritan bermotif mulai dari semen gede sawat lar dan seterusnya, sedangkan bebetnya bermotif mulai dari parang rusak gendreh dan seterusnya. Canggah dari sultan diperbolehkan memakai dodot danbebet prajuritan serta bebet bermotif sama dengan yang dipakai oleh buyut sultan. Wareng dari sultan dan generasi ke bawahnya diperbolehkan memakai dodot dan bebet prajuritan bermotif bebas asalkan 
bukan motif-motif larangan dan bukan berlatar putih, sedangkan bebetnya motif parang-parangan yang bukan parang rusak. Namun motif parang-parangan tersebut haruslah seling (harus ada ornamen tambahan) dan tidak boleh byur (bermotif satu macam saja dan tidak ada ornamen tambahan). Bagi patih diperbolehkan memakai dodot dan bebet prajuritan mulai dari motif parang rusak gendreh dan seterusnya. Sedangkan bebetnya bermotif parang rusak barong dan seterusnya. Bagi para abdi seperti penghulu hakim, wedana gede prajurit, bupati nayoko jaba jero, diperbolehkan memakai dodot blenggen dan bebet prajuritan mulai dari motif semen gede sawat gruda dan seterusnya, sedangkan bebetnya bermotif mulai dari parang rusak gendreh dan seterusnya. Bagi para abdi seperti bupati patih di kadipaten, buipati polisi, penghulu landrap, wedana keparak pada Gusti (nyai riyo), bupati enom, riyo bupati enom diperbolehkan memakai dodot, bebet prajuritan mulai dari motif semen gede sawat gruda dan seterusnya, sedangkan bebetnya bermotif dari parang rusak gendreh dan seterusnya. Bagi para abdi yang pangkatnya di bawah riyo bupati enom dan yang bukan berpangkat bupati enom diperbolehkan memakai dodot bermotif bebas asalkan bukan batik-batik larangan dan harus berlatar hitam demikian juga dengan bebet prajuritannya. Sedangkan bebetnya bermotif parangparangan yang bukan parang rusak. Tetapi kain bermotif parang-parangan tersebut harus seling tidak buleh byur. Bagi istri patih dan istri-istri abdi yang berpangkat di bawahnya, walaupun mereka masih keturunan sultan dan diperbolehkan memakai kain batik yang lebih tinggi kedudukannya dari suaminya, namun mereka diperbolehkan juga memakai kain yang sama dengan yang dipakai suami mereka. Akan tetapi, jika yang menjadi abdi itu perempuan, dan suaminya masih keturunan sultan, sang suami tidak boleh memakai kain batik yang sama dengan istrinya.

\section{Simbol}

Yang termasuk simbol dalam Batik Larangan di Yogyakarta adalah nama, jenis warna, corak kain, struktur corak, makna, dan fungsi kain, karena bagian-bagian tersebut mewakili dari keseluruhan maksud yang disampaikan dalam suatu sistem.Hal-hal yang disimbolkan pada masing-masing jenis Batik Larangan mengandung arti yang baik dan memiliki makna filosofi yang sangat mendalam.Bagi pemakainya diharapkan dapat memberikan pancaran kekuatan seperti yang terkandung dalam makna filosofinya.Sebagai contoh,motif parang rusak hanya diperbolehkan untuk raja, permaisuri, dan putra mahkota. Untuk raja motif parang rusak barong, permaisuri parang rusak gendreh dan untuk putra mahkota parang rusak klitik.Masing-masing hanya dibedakan dengan ukurannya. Urutan paling atas menandakan bahwa kain tersebut memiliki kedudukan tinggi. Makin ke bawah urutan kain-kain tersebut, semakin rendah kedudukannya. Orang-orang yang boleh mengenakannya jumlahnya lebih banyak dibanding kain-kain urutan di atasnya. Jadi susunan motif-motif kain tersebut menunjukkan hirarki sosial dan status sosial.

Bagi masyarakat Yogyakarta busana dianggap sebagai salah satu sarana penegak kewibawaan, terutama bagi sultan dan kalangan bangsawan yang tinggal di keraton.Kaum bangsawan percaya bahwa kain batik yang mereka kenakan dapat memberikan pancaran religius magis. Selain itu, batik merupakan simbol status sosial dalam kehidupan bermasyarakat (Condronegoro, 1995: 18-19). Hal ini ternyata berkaitan erat dengan konsep kepemimpinan tradisional Jawa,seperti yang diyatakan oleh Soemarsaid yaitu konsep kawula gusti. Di mana raja sebagai seorang pemimpin diumpakan sebagai gusti.Gusti adalah konsep perumpamaan bahwa raja harus memiliki sifat-sifat Ketuhanan.Bahwa sultan sebagai wakil Tuhan dimuka bumi. Dia adalah penguasa sah di dunia dan merupakan perantara tunggal yang harus dilalui manusia untuk mencapai Tuhan, demikian juga sebaliknya dia harus dilalui Tuhan untuk manusia (Moertono, 1985: 42). Sebagai wali Tuhan, Sultan ditempatkan pada tampuk tata masyarakat jauh di atas jangkauan orang biasa. Dia merupakan sumber kekuasaan yang pokok, menyeluruh dan tunggal dalam negara. Sebagai pemimpin, seorang Sultan harus mempunyai dua unsur yaitu kekuasaan dan kewibawaan. Kedua unsur itu harus saling membantu karena untuk menambah kekuatan diperlukan kewibawaan yang besar (Depdikbud, 1976: 164). Kekuasaan dalam konsep Jawa erat hubungannya dengan kesakten (Surbakti, 1992:81).Untuk melegitimasikan kekuasaan dan kewibawaannya sebagai penguasa tertinggi di Yogyakarta, Sultan harus memperlihatkan dengan "Kultus kemegahan". 
Kultus kemegahan ini terdiri dari 2 jenis sarana yang satu bersifat bukan materi atau abstrak dan lainnya lebih konkret, lebih bisa dilihat. Sarana yang bersifat abstrak menyangkut aspek spiritual (kesempurnaan batin), seperti kesaktian yang dimiliki raja dan silsilah raja, sedangkan batik dapat digolongkan sebagai sarana kultus kemegahan yang bersifat konkret. Dengan mengenakan kain tertentu yang memiliki motif tertentu dengan arti yang dalam dianggap dapat menambah kewibawannya (Moertono, 1985: 72-73).

Busana atau pakaian menurut A. Laurie merupakan ekspresi dari identitas seseorang karena saat kita memilih pakaian, baik di toko atau di rumah, berarti kita mendefinisikan dan mendeskripsikan diri sendiri.Sedangkan Kuper menekankan arti penting berpakaian sebagai suatu ekspresi dari identitas social, asal usul, komitmen dan kesetiaan individu, tidaklah mengherankan bahwa orang-orang seharusnya memandang pakaian hampir seperti perpanjangan diri mereka sendiri. Singkatnya, sekarang dapat kita mengerti mengapa hubungan seseorang dengan pakaiannya bersifat langsung dan lebih akrab daripada hubungannya dengan semua objek materi yang lain(Laurie dan Kuper dalam Nordholt (ed), 2005: 1-4). Mari S. Condronegoro menyatakan bahwa berbagai symbol yang tercermin dari pakaian merupakan alat komunikasi yang memberikan arti bagi masing-masing pribadi (Condronegoro, 1995:26). Dengan demikian, dapat kita katakan bahwa pakaian memberikan penggambaran bagi pemakainya. Pakaian menunjukkan indentitas pemakainya.Demikian pula batik larangan di Yogyakarta.

\section{SIMPULAN}

Mempelajari Batik Larangan di Yogyakarta merupakan salah satu bentuk dokumentasi ulang dan kontribusi dalam menjaga produk budaya bangsa. Dari pembahasan dan analisis, tampak bahwa karakter masayarakat Jawa yang sangat menjunjung tinggi hierarki sosial. Melalui kain Batik Larangan leluhur masyarakat Jawa ingin mengingatkan generasi penerusnya untuk menjaga keharmonisan, keselerasan, dan keseimbangan dalam hidup serta bijaksana dalam menyikapi hidup. Busana tertanya tidak hanya berfungsi sebagai penutup anggota tubuh saja, tetapi juga menggambarkan identitas pemakainya.Bahkan bagi masayarakat Yogyakarta busana bagi seorang pemimpin berfungsi untuk melegitimasi kedudukannya. Melalui busana yang dikenakan dalam hal ini kain batik diharapkan kultus kemegahan dapat diperolehnya

\section{DAFTAR PUSTAKA}

Condronegoro, M. (1995). Busana Adat Keraton Yogyakarta 1877-1937. Yogyakarta: Pustaka satama.

Depdikbud. (1998). Khazanah Budaya Nusantara. Jakarta: Proyek Pengembangan Media Kebudayaan Direktorat Jendral Departemen Pendidikan dan Kebudayaan.

Dewi, A. K. (2010, 12 Oktober). Pengantar Semiotika. Diunduh Januari 2013 dari http://www.isidps.ac.id/berita/semiotika-bagian-i

Hamzuri. (1981). Batik Klasik. Jakarta: Djambatan.

Hidajat, R. (2004). Kajian strukturalisme simbolik mitos jawa pada motif batik berunsur alam. Bahasa dan Seni, 32(2). Diakses Januari 2013 dari http://sastra.um.ac.id/wpcontent/uploads/2009/10/Kajian-Strukturalisme-Simbolik-MitosJawa-pada-Motif-Batik-Berunsur-Alam.pdf. 
Himpunan Wastraprema. (1990). Sekaring Jagad Ngayogyakarta Hadiningrat. Jakarta: Midas Surya Grafindo.

Moertono, S. (1985). Negara dan Usaha Bina Negara di Jawa Masa Lampau. Jakarta: Obor.

Sarwono. (2009, 9 Juni). Kajian Semiotika Pada Batik Klasik. Diakses Febuari 2013 dari http://sarwono.staff.uns.ac.id/kajian-semiotika-pada-motif-batik-klasik/

Soerjanto, T. T.( 1991).KlasifikasiMotifBatik. Yogyakarta: Balai Penelitian Kerajinan dan Batik.

Susanto, S. (1973). Seni Kerajinan Batik di Indonesia. Jakarta: Deperindag RI.

Tirtaatmadja, N. (1993). Batik: Pola dan Tjorak-Pattern dan Motif. Jakarta: Djambatan.

Wahyu, A. (2012). Chick in Batik. Jakarta: Erlangga. 